\title{
DESEMPENHO AGRONÔMICO E QUALITATIVO DE CULTIVARES DE CEVADA CERVEJEIRA NO ESTADO DO ESPÍRITO SANTO
}

\author{
Jacimar Luis de Souza ${ }^{1}$, Euclydes Minella², Rogério Carvalho Guarçoni ${ }^{3}$, Luiz Fernando Favarato ${ }^{4}$, \\ Camila Santos Teixeira ${ }^{5}$
}

\begin{abstract}
RESUMO - Com a expansão do mercado de cervejas artesanais, a recomendação de cultivares de cevada cervejeira com bom potencial produtivo no estado do Espírito Santo poderá se tornar uma nova alternativa tecnológica para os agricultores. Assim, objetivou-se avaliar o comportamento agronômico e a qualidade de três cultivares de cevada oriundas do programa de melhoramento genético da Embrapa, na região serrana do estado do Espírito Santo, a $950 \mathrm{~m}$ de altitude, município de Domingos Martins. O delineamento experimental foi em blocos casualizados, com oito repetições e três tratamentos referentes às cultivares BRS Sampa, BRS Kalibre e BRS Brau, obtidas do programa de melhoramento genético da Embrapa Trigo. As parcelas foram compostas por 4 fileiras de plantas de $2 \mathrm{~m}$ de comprimento, totalizando $2 \mathrm{~m}^{2}$. O número de grãos por espiga não se diferenciou entre as cultivares, mas o peso de mil grãos variou significativamente, com destaque para a cv. BRS Kalibre, com média de 59,3 g, contra 55,6 g e 51,8 g das cultivares BRS Brau e BRS Sampa, respectivamente. Os níveis de produtividade de grãos obtidos foram satisfatórios, com médias de $4.870,4.977$ e $5.593 \mathrm{~kg}$ ha $^{-1}$ para as cultivares BRS Sampa, BRS Brau e BRS Kalibre, respectivamente. Os grãos de cevada mostraramse adequados à transformação em malte cervejeiro, uma vez que todas as cultivares apresentaram mais que $85 \%$ dos grãos classe 1 (maior que $2,5 \mathrm{~mm}$ ), poder germinativo acima de $95 \%$ e teores de proteína na faixa de 9,0 a $12,0 \%$.
\end{abstract}

Palavras chave: agroecologia, cultivo orgânico, Hordeum vulgare, melhoramento genético, produção de cerveja.

\section{AGRONOMIC AND QUALITATIVE PERFORMANCE OF BARLEY CULTIVARS FOR BREWING IN THE ESPÍRITO SANTO STATE}

\begin{abstract}
With the growth of the artisanal beer market, the recommendation of breeding barley cultivars with good productive potential in the Espírito Santo state of may become a new technological alternative for farmers. The objective of this study was to evaluate the agronomic behavior and quality of three barley cultivars from the Embrapa breeding program, in the highland region of the Espírito Santo state, at 950 $m$ altitude, Domingos Martins municipality. The experimental design was a randomized complete block design, with eight replications and three treatments referring to cultivars BRS Sampa, BRS Kalibre and BRS Brau, obtained from the breeding program of Embrapa Wheat. The plots were composed of 4 rows of $2 \mathrm{~m}$ long plants, totaling $2 \mathrm{~m}^{2}$. The number of grains per spike did not differ among cultivars, but the weight of a thousand grains varied significantly, with emphasis on cv. BRS Kalibre, averaging $59.3 \mathrm{~g}$, against $55.6 \mathrm{~g}$ and $51.8 \mathrm{~g}$ of the BRS Brau and BRS Sampa cultivars, respectively. Grain productivity levels were quite satisfactory
\end{abstract}

${ }^{1}$ Engenheiro Agrônomo, Doutor, Instituto Capixaba de Pesquisa, Assistência Técnica e Extensão Rural, Br 262, Km 94, 29375-000, Venda Nova do Imigrante, Espírito Santo, Brasil. jacimarsouza@incaper.es.gov.br (Autor para correspondência)

${ }^{2}$ Engenheiro Agrônomo, Pós-Doutor, Embrapa Trigo, Rodovia BR 285, Km 294, 99050-970, Passo Fundo, Rio Grande do Sul, Brasil. euclydes.minella@embrapa.br

${ }^{3}$ Engenheiro Agrícola, Doutor, Instituto Capixaba de Pesquisa, Assistência Técnica e Extensão Rural, Br 262, Km 94, 29375 000, Venda Nova do Imigrante, Espírito Santo, Brasil. rogerio.guarconi@incaper.es.gov.br

${ }^{4}$ Engenheiro Agrônomo, Doutor, Instituto Capixaba de Pesquisa, Assistência Técnica e Extensão Rural, Br 262, Km 94, 29375-000, Venda Nova do Imigrante, Espírito Santo, Brasil. luiz.favarato@incaper.es.gov.br

${ }^{5}$ Engenheira Agrônoma, Mestranda em Agronomia/Fitotecnia, Universidade Federal do Ceará, Av. Mister Hull, s/n, Pici, 60455-760, Fortaleza, Ceará, Brasil.teixeira.camila@outlook.com 
compared to the yields observed in other regions, with averages of 4,870, 4,977 and 5,593 $\mathrm{kg} \mathrm{ha}^{-1}$ for the cultivars BRS Sampa, BRS Brau and BRS Kalibre, respectively. Barley grains were suitable for processing in brewing malt, since all presented more than $85 \%$ of class 1 grains (greater than $2.5 \mathrm{~mm}$ ) and protein contents from 9.0 to $12.0 \%$.

Keywords: agroecology, brewing, genetic breeding, Hordeum vulgare, organic crop.

\section{INTRODUÇÃO}

A cevada é um cereal de inverno de grande importância econômica no mundo. É uma cultura com múltiplos usos, utilizada para a produção cervejeira, para ração animal e na alimentação humana. No Brasil, devido às alternativas mais baratas de alimentação animal e humana, como o milho e a soja, mais de $95 \%$ da cevada é cultivada para fins cervejeiros (Borowski, 2012; Ferreira, 2015).

O mercado de cervejas artesanais tem crescido muito nos últimos anos no Brasil, aumentando a demanda por insumos, especialmente pelo malte de cevada, que é a base do sistema produtivo. Atualmente a produção de cevada está concentrada na região sul do Brasil. Entretanto, a Embrapa tem desenvolvido, por meio do seu programa de melhoramento genético, cultivares de cevada cervejeira de duas fileiras, com potencial produtivo para outras regiões brasileiras, como locais de altitude do sudeste brasileiro (Minella, 2009).

Em nível mundial 65,8\% da produção de cevada se destina a alimentação animal, $18,9 \%$ ao processamento industrial, $6,9 \%$ à reserva de sementes, $4,7 \%$ à alimentação humana direta e 0,4\% a outros usos. Em 2016, a área brasileira plantada com cevada foi de 95,6 mil hectares, com produtividade média de $3.920 \mathrm{~kg} \mathrm{ha}^{-1}$ e produção total de 374,8 mil toneladas (Companhia Nacional de Abastecimento, 2017). Em contrapartida, a demanda brasileira de malte de cevada foi de 1,2 milhões de toneladas (Ferreira, 2015), sendo que menos de $1 / 4$ desta demanda interna é atendida pela produção nacional. Isto demonstra a existência de um mercado potencial para suprimento desta demanda por parte dos agricultores.

A escolha de cultivar mais competitiva na região de intenção de cultivo é fator decisivo para o sucesso do empreendimento. Na região sul do Brasil a cadeia produtiva da cevada está bem desenvolvida, com zoneamento das localidades e épocas mais apropriadas de cultivo da cultura para a safra 2015/2016 (Minella, 2015).
A estreita relação do material genético de cevada com o ambiente de cultivo também é relatada por Borowski (2012), quando avaliou as características agronômicas e de qualidade, de seis cultivares de cevada cervejeira no Rio Grande do Sul. Todas apresentaram potencial produtivo, variando de 3.081 a $5.398 \mathrm{~kg} \mathrm{ha}^{-}$ ${ }^{1}$, identificando diferenças de resposta entre as localidades regionais avaliadas (Victor Graeff, Passo Fundo e Lagoa Vermelha).

Giaretta et al. (2017) verificaram que as cultivares BRS Brau, BRS Korbel, BRS Quaranta, BRS Elis e ANA 01 apresentaram boa adaptação às condições climáticas de Santa Catarina, cultivadas na região de São José do Cedro, situada em torno de $720 \mathrm{~m}$ altitude. Os autores relataram que todas as cultivares apresentaram rendimento comercial acima da média estadual. Caierão et al. (2006), avaliando a cultivar MN 716 em 32 ambientes na região sul do Brasil, relatou produtividade média de $3.100 \mathrm{~kg} \mathrm{ha}^{-1}$, com classificação comercial de $88 \%$ de grãos acima de $2,5 \mathrm{~mm}$, com boa qualidade cervejeira e teor de proteína de $11,0 \%$.

No cerrado sul-mato-grossense, Sanches et al. (2015) avaliaram cultivares de cevada sob diferentes lâminas de irrigação, no município de Chapadão do Sul/MS. O clima local é classificado como tropical úmido, a temperatura anual fica compreendida entre 13 a 28 ${ }^{\circ} \mathrm{C}$, com precipitação pluviométrica média anual de 1.850 $\mathrm{mm}$. Os autores obtiveram produtividades bastante promissoras, com rendimentos máximos de grãos de $5.848,5.449$ e $4.767 \mathrm{~kg} \mathrm{ha}^{-1}$ para as cultivares BRS Sampa, BRS Manduri e BRS 195, respectivamente.

A adaptação da cultivar BRS 180 em condições irrigadas do cerrado brasileiro, foi avaliada e verificouse elevada produtividade, resistência ao acamamento e baixos teores de proteína, que vêm atender às demandas agronômicas e ao padrão de qualidade para a indústria. Em parcelas experimentais atingiu-se rendimentos de até $8.920 \mathrm{~kg} \mathrm{ha}^{-1}$ e em nível de lavouras comerciais de até $6.000 \mathrm{~kg} \mathrm{ha}^{-1}$ (Silva et al., 2000). Nesta mesma região, Amabile et al. (2008) relataram que a cultivar 
BRS Deméter apresentou potencial produtivo de grãos acima de $5.000 \mathrm{~kg} \mathrm{ha}^{-1}$, com classificação comercial primeira variando de $85 \%$ a $92 \%$ de grãos acima de $2,5 \mathrm{~mm}$ e de boa qualidade industrial para malte, com teor de proteína abaixo de $12 \%$ na maioria dos ambientes.

Em nível internacional encontram-se vários trabalhos científicos que relatam o comportamento produtivo de cultivares de cevada em diversos ambientes de cultivo, a exemplo de Siddique et al. (1989) na Austrália (com rendimento médio de 2,1 t ha- ${ }^{-1}$ ), de HauggaardNielsen \& Jensen (2001) na Dinamarca (com rendimento médio de 5,9 $\mathrm{t} \mathrm{ha}^{-1}$ ) e de Leistrumaite et al. (2008) na Lituânia (com rendimento médio de 3,2 $\mathrm{t} \mathrm{ha}^{-1}$ ).

A recomendação de cultivares de cevada cervejeira, com bom potencial produtivo no estado do Espírito Santo, poderá se tornar uma nova alternativa tecnológica para os agricultores das regiões de montanha do estado do Espírito Santo, devido às baixas temperaturas nos meses de outono-inverno, similares àquelas das regiões sul do Brasil. Assim, visando colaborar com a expansão do setor na região sudeste do Brasil, objetivou-se avaliar o comportamento agronômico e a qualidade de três cultivares de cevada, previamente identificadas como de bom potencial para a produção de grãos nas condições de altitude do estado do Espírito Santo.

\section{MATERIAL E MÉTODOS}

O experimento foi executado na Unidade de Referência em Agroecologia do INCAPER, no município de Domingos Martins, na região centro-serrana do estado do Espírito Santo. O clima é classificado como Cfa, de acordo com Köppen e Geiger, com clima temperado úmido e verão quente, altitude média de $820 \mathrm{~m}$, temperatura média anual de 17,8 a $19,4^{\circ} \mathrm{C}$ e pluviosidade média anual de $1300 \mathrm{~mm}$ (ALVARES et al., 2013). A altitude medida no local do experimento foi de $950 \mathrm{~m}$.

A área da Unidade de Agroecologia é cultivada com manejo orgânico desde 1990, possuindo 2,5 ha, subdivididos em 15 talhões de solos, onde as experimentações são realizadas. Os princípios e técnicas de manejo orgânico adotados seguem as orientações descritas por Souza e Resende (2014). A pesquisa foi desenvolvida em um Latossolo Vermelho Amarelo Distrófico Argiloso, no Talhão 02, no ano de 2017, com a seguinte caracterização de solo, na profundidade $0-20 \mathrm{~cm}$ : pH em água $(6,2)$; matéria orgânica (2,6 dag $\left.\mathrm{kg}^{-1}\right)$; fósforo (92 $\left.\mathrm{mg} \mathrm{dm}^{-3}\right)$; potássio $\left(95 \mathrm{mg} \mathrm{dm}^{-3}\right)$; cálcio $\left(4,6 \mathrm{cmol}_{\mathrm{c}} \mathrm{dm}^{-3}\right)$; magnésio $\left(0,6 \mathrm{cmol}_{\mathrm{c}}\right.$ $\left.\mathrm{dm}^{-3}\right)$; soma de bases $\left(5,5 \mathrm{cmol}_{\mathrm{c}} \mathrm{dm}^{-3}\right) ; \mathrm{H}+\mathrm{Al}\left(3,6 \mathrm{cmol}_{\mathrm{c}}\right.$ $\left.\mathrm{dm}^{-3}\right) ; \mathrm{Al}^{+3}\left(0,0 \mathrm{cmol}_{\mathrm{c}} \mathrm{dm}^{-3}\right)$; capacidade de troca catiônica potencial $\left(9,1 \mathrm{cmol}_{\mathrm{c}} \mathrm{dm}^{-3}\right)$ e saturação por bases (60\%) (Embrapa, 2011 e Yeomans \& Bremner, 1988).

A implantação do experimento ocorreu em 26 de junho de 2017, com três cultivares obtidas do programa de melhoramento genético da Embrapa Trigo, com potencial para a produção nas condições climáticas nos locais de maior altitude da região sudeste do Brasil - BRS Sampa, BRS Kalibre e BRS Brau. A origem e características das cultivares estão apresentadas na Tabela 1.

O delineamento experimental foi em blocos casualizados, com três tratamentos referentes às cultivares e oito repetições. As parcelas foram compostas por 4 fileiras de plantas de $2 \mathrm{~m}$ de comprimento, totalizando $2 \mathrm{~m}^{2}$. A semeadura foi feita em sulcos distanciados $25 \mathrm{~cm}$, utilizando-se a densidade de 340 sementes por $\mathrm{m}^{2}$. Devido aos distintos tamanhos de grãos entre as cultivares, os gastos de sementes foram de 16,0 $\mathrm{g} \mathrm{m}^{-2}$ para a cv. Sampa (160 $\left.\mathrm{kg} \mathrm{ha}^{-1}\right)$; $15,6 \mathrm{~g} \mathrm{~m}^{-2}$ para a cv. Kalibre $\left(156 \mathrm{~kg} \mathrm{ha}^{-1}\right)$ e de $14,4 \mathrm{~g} \mathrm{~m}^{-2}$ para a cv. Brau (144 kg ha'-1).

Para caracterização e avaliação do desempenho agronômico das cultivares foram analisadas algumas características descritas em artigos técnico-científicos com esta espécie, a saber: 1) Altura de planta: distância média medida da superfície do solo até o ápice da espiga sem as aristas em 20 plantas aleatórias por parcela; 2) Perfilhos por planta: número médio de hastes obtido na contagem em 10 plantas aleatórias por parcela; 3) Comprimento da espiga: obtido da média de 20 espigas sem as aristas aleatórias de cada parcela; 4) Número de grãos por espiga: obtido da contagem dos grãos de 20 espigas aleatórias por parcela; 5) Peso de mil grãos: determinado pela pesagem de 100 grãos após a debulha; 6) Densidade de espigas: contagem do número de espigas comerciais por $\mathrm{m}^{2}$; 7) Produtividade de grãos em $\mathrm{kg} / \mathrm{ha}$ : obtida da pesagem total dos grãos de cada parcela, após a secagem até $13 \%$ de umidade; e 8) Peso médio de espiga: determinado pela fração entre o peso de grãos por $\mathrm{m}^{2}$ e o número de espigas por $\mathrm{m}^{2}$.

Após as avaliações quantitativas foi realizada a avaliação qualitativa dos grãos: 1) Poder germinativo: porcentagem de sementes germinadas com raízes e 
Tabela 1 - Origem (pedigree) e região de adaptação fenotípica das cultivares de cevada avaliadas

\begin{tabular}{lccc}
\hline Cultivar & Pedigree & Adaptação & Altura \\
\hline BRS Brau & MN698/3/BRS195//Schooner/PFC 9216 & RS, SC, PR,MG, GO & Baixa \\
BRS Kalibre & PFC 9325/Merit & SP & Média \\
BRS Sampa & BRS 195//PFC 8590/PFC 9205 & PR, SP & Média \\
\hline
\end{tabular}

epicótilo emergidos de 30 sementes dispostas em papel filtro umedecido, em placas de petri, contadas após 7 dias; 2) Classificação comercial: expressa em porcentagem de grãos Classe 1 (retidos em peneira de células retangulares 2,5 $\mathrm{mm}$ de largura); e 3) Teor de proteínas: determinado em via úmida de amostra em laboratório da Embrapa Trigo.

As análises e procedimentos estatísticos ocorreram por meio de análises de variâncias, sendo as médias comparadas pelo teste de Tukey a 5\% de probabilidade de erro. Para o agrupamento das cultivares foi utilizado o método de Tocher, utilizando a distância Euclidiana Média. Foi utilizado o programa Saeg para as análises estatísticas.

\section{RESULTADOS E DISCUSSÃO}

Os valores médios semanais das temperaturas mínimas, máximas e médias do ar, no período experimental de 26 de junho a 23 de outubro de 2017 , estão apresentados na Figura 1A. Verificou-se variações térmicas significativas neste período de cultivo, com a temperatura mínima de $7,7^{\circ} \mathrm{C}$ na $6^{\mathrm{a}}$ semana e a máxima de $27,5^{\circ} \mathrm{C}$ na $15^{\mathrm{a}}$ semana. A temperatura média semanal variou de $13,1^{\circ} \mathrm{C}$ a $19,2^{\circ} \mathrm{C}$. Houve treze precipitações pluviais em todo o período experimental, totalizando $143,0 \mathrm{~mm}$ de chuva e a umidade relativa do ar ficou compreendida entre 68,9 e 84,5\% (Figura 1B).

\section{Características agronômicas}

BRS Brau, colhida 18/10/2017, 114 dias após plantio, foi cinco dias mais precoce que as cultivares BRS Sampa e BRS Kalibre, colhidas em 23/10/2017.

Os valores médios obtidos das características agronômicas analisadas mostram que BRS Sampa e BRS Kalibre cresceram mais e atingiram comprimento da espiga maior que BRS Brau. BRS Sampa produziu o maior número de perfilhos por planta e BRS Kalibre o menor, ficando BRS Brau entre as duas (Tabela 2). $\mathrm{O}$ grau de perfilhamento das cultivares foi maior que os relatados por Ferreira (2015) para cultivares testada em Ponta Grossa/PR.

O número de grãos por espiga não se diferenciou entre as cultivares e os valores foram semelhantes aos obtidos em outros estudos, a exemplo de Borowski (2012) no sul do Brasil, que obteve com as cultivares BRS Elis, BRS Caue, MN 743, MN 610, BRS 195 e Scarlett, médias de 20,2 24,3, 25,5, 25,8, 24,2 e 23,9, respectivamente.

O peso de mil grãos variou significativamente entre as cultivares, com destaque para BRS Kalibre, com média de 59,3 g, contra 55,6 g e 51,8 g de BRS Brau e BRS Sampa, respectivamente, indicando bom enchimento de grãos no ambiente local (Tabela 2). Os pesos de grãos superaram os obtidos com outras cultivares em outras regiões do Brasil e do mundo. Amabile et al. (2008) relataram pesos de 45,0 g, 42,5 g e 42,0 g para as cultivares BRS Deméter, BRS 195 e BRS 180 , respectivamente, em cultivo no cerrado brasileiro. Borowski (2012) relatou valores de 44,3 g, 44,2 g, 44,6 g, 44,3 g, 44,4 g e 44,2 g, para as cultivares BRS Elis, BRS Cauê, MN 743, MN 610, BRS 195 e Scarlett, respectivamente, cultivadas no sul do Brasil. Siddique et al. (1989) relataram peso de 32,4 g para mil grãos da cultivar O'Connor, cultivada na Austrália.

As três cultivares apresentaram desempenho semelhante quanto à densidade de espigas por $\mathrm{m}^{2}$, rendimento de grãos e poder germinativo, não havendo diferenças estatísticas entre elas (Tabela 3). Observouse apenas destaque da cultivar BRS Kalibre com maior peso médio de espigas, mas não diferenciando estatisticamente da cultivar BRS Brau e superior a cultivar BRS Sampa, ocasionado pelo o maior peso médio dos grãos, uma vez que o número de grãos por espiga foi semelhante entre as cultivares.

Os níveis de produtividade de grãos obtidos no local foram bastante satisfatórios comparados aos rendimentos observados em outras regiões. Caierão et al. (2006), avaliando a cultivar MN 716 em 32 

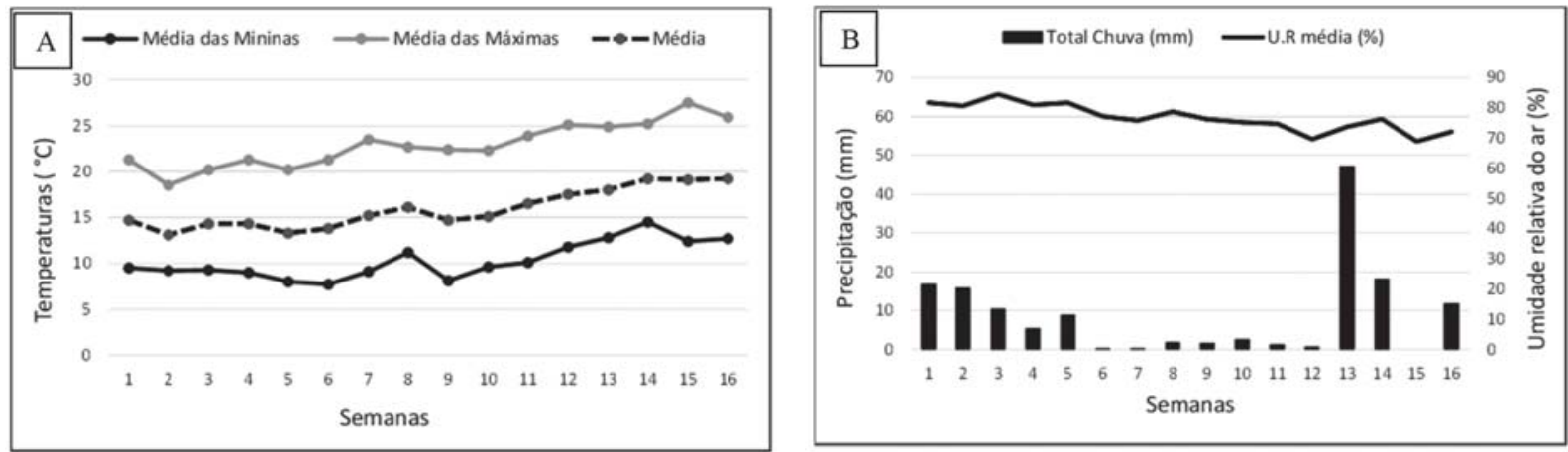

Figura 1 - Médias semanais da temperatura do ar, precipitação e umidade relativa do ar no período de cultivo da cevada cervejeira, de junho a outubro de 2017. Domingos Martins/ES.

Tabela 2 - Médias altura de planta, número de perfilhos por planta, comprimento da espiga, número de grãos por espiga e peso de mil grãos, de três cultivares de cevada cervejeira, obtidas em $2017^{1}$

\begin{tabular}{|c|c|c|c|c|c|}
\hline $\begin{array}{l}\text { Cultivares de } \\
\text { cevada cervejeira }\end{array}$ & $\begin{array}{c}\text { Altura de } \\
\text { planta }(\mathrm{cm})\end{array}$ & $\begin{array}{l}\mathrm{N}^{0} \text { de perfilhos } \\
\text { por planta }\end{array}$ & $\begin{array}{l}\text { Comprimento da } \\
\text { espiga }(\mathrm{cm})\end{array}$ & $\begin{array}{l}\mathrm{N}^{\circ} \text { de grãos } \\
\text { por espiga }\end{array}$ & $\begin{array}{l}\text { Peso de mil } \\
\text { grãos }(\mathrm{g})\end{array}$ \\
\hline BRS Sampa & 92,4 a & $3,1 \mathrm{a}$ & $7,2 \mathrm{a}$ & 23,4 a & $51,8 \mathrm{~b}$ \\
\hline BRS Kalibre & $90,8 \mathrm{a}$ & $2,2 \mathrm{~b}$ & 7,1 a & $22,7 \mathrm{a}$ & 59,3 a \\
\hline BRS Brau & $80,9 \mathrm{~b}$ & $2,6 a b$ & $6,2 \mathrm{~b}$ & 22,4 a & $55,6 \mathrm{ab}$ \\
\hline Média & 88,0 & 2,7 & 6,8 & 22,8 & 55,6 \\
\hline
\end{tabular}

${ }^{1}$ Médias seguidas de pelo menos uma mesma letra na coluna, não diferem entre si pelo teste de Tukey a $5 \%$ de probabilidade.

Tabela 3 - Densidade de espigas por $\mathrm{m}^{2}$, produtividade de grãos, peso médio de espiga e poder germinativo, avaliadas em três cultivares de cevada cervejeira, $2017^{1}$

\begin{tabular}{lcccc}
\hline $\begin{array}{l}\text { Cultivares de } \\
\text { cevada cervejeira }\end{array}$ & $\begin{array}{c}\text { Densidade de } \\
\text { espigas por } \mathrm{m}^{2}\end{array}$ & $\begin{array}{c}\text { Produtividade de } \\
\text { grãos }\left(\mathrm{kg} \mathrm{ha}^{-1}\right)\end{array}$ & $\begin{array}{c}\text { Peso médio de } \\
\text { espiga (g) }\end{array}$ & $\begin{array}{c}\text { Poder } \\
\text { germinativo (\%) }\end{array}$ \\
\hline BRS Sampa & $403,5 \mathrm{a}$ & $4870,4 \mathrm{a}$ & $1,21 \mathrm{~b}$ & 96,8 \\
BRS Kalibre & $418,0 \mathrm{a}$ & $5592,9 \mathrm{a}$ & $1,34 \mathrm{a}$ & 96,2 \\
BRS Brau & $399,6 \mathrm{a}$ & $4976,7 \mathrm{a}$ & $1,25 \mathrm{ab}$ & 96,6 \\
Média & 407,0 & 5146,7 & 1,27 & $\mathrm{a}$ \\
\hline
\end{tabular}

${ }^{1}$ Médias seguidas de pelo menos uma mesma letra na coluna, não diferem entre si pelo teste de Tukey a $5 \%$ de probabilidade.

ambientes na região sul do Brasil, relataram produtividade média de $3.100 \mathrm{~kg} \mathrm{ha}^{-1}$. Amabile et al. (2008), relataram potencial produtivo de grãos acima de $5.000 \mathrm{~kg} \mathrm{ha}^{-1}$ para a cultivar BRS Deméter, em condições irrigadas no cerrado. Sanches et al. (2015), obtiveram rendimentos máximos de 5.848, 5.449 e $4.767 \mathrm{~kg} \mathrm{ha}^{-1}$ para as cultivares BRS Sampa, BRS Manduri e BRS 195, respectivamente, no cerrado de Mato grosso do Sul.

O poder germinativo acima de $96 \%$ observado para as três cultivares comprovam boa qualidade para atender à indústria de malte, uma vez que o mínimo exigido pelas matérias é de 95\% (Ferreira, 2015).

\section{Teste de agrupamento das cultivares}

As cultivares BRS Sampa e BRS Brau formam o primeiro grupo e a cultivar BRS Kalibre o segundo grupo, utilizando o método de agrupamento de otimização Tocher, com as variáveis $\mathrm{n}^{\circ}$ de perfilhos por planta, $\mathrm{n}^{\circ}$ de grãos por espiga e $\mathrm{n}^{\circ}$ de espigas comerciais por $\mathrm{m}^{2}$, contribuindo cada uma com $33,3 \%$ para o agrupamento (Tabela 4). 


\section{Qualidade dos grãos para a indústria de malte}

Além do poder germinativo já discutido anteriormente, outros dois parâmetros importantes para atender às especificações da indústria de malte, referemse à classificação comercial (grãos classe 1) e ao teor de proteínas (Tabela 5). As análises são apenas informativas e não foram submetidas à análise estatística, pois foram feitas sem repetição e delineamento. Os resultados indicam que foram produzidos grãos de cevada adequados à transformação em malte cervejeiro (grãos classe 1 , superiores a $2,5 \mathrm{~mm}>85 \%$ e teor de proteína acima de 9,0 e inferior a 12,0\%). Embora os dados sejam de apenas uma amostra, pode se inferir que a região apresenta em tese potencial para produzir cevada para cerveja.

Tabela 4 - Grupos de tratamentos e contribuição das variáveis para o agrupamento ${ }^{1}$

\begin{tabular}{|c|c|}
\hline \multicolumn{2}{|l|}{ Grupos } \\
\hline Grupo & Cultivares \\
\hline 1 & BRS Sampa e BRS Brau \\
\hline 2 & BRS Kalibre \\
\hline \multicolumn{2}{|c|}{ Contribuição das variáveis } \\
\hline Variável & Contribuiçãa \\
\hline Altura de planta & 0,00 \\
\hline $\mathrm{N}^{\circ}$ de perfilhos por planta & 33,3 \\
\hline Comprimento da espiga & 0,00 \\
\hline $\mathrm{N}^{\circ}$ de grãos por espiga & 33,3 \\
\hline Peso de mil grãos & 0,00 \\
\hline $\mathrm{N}^{\mathrm{o}}$ de espigas comerciais por $\mathrm{m}^{2}$ & 33,3 \\
\hline Produtividade de grãos & 0,00 \\
\hline Peso médio de espiga & 0,00 \\
\hline Poder germinativo & 0,00 \\
\hline
\end{tabular}

${ }^{1}$ Agrupamento de Tocher, pelo teste de Tukey a $5 \%$ de probabilidade.

Tabela 5 - Análise qualitativa de cultivares de cevada cervejeira, 2017

\begin{tabular}{lcc}
\hline Cultivares & $\begin{array}{c}\text { Grãos classe } \\
1(\%)\end{array}$ & $\begin{array}{c}\text { Teor de } \\
\text { proteína }(\%)\end{array}$ \\
\hline BRS Sampa & 95,3 & 9,6 \\
BRS Kalibre & 97,6 & 9,8 \\
BRS Brau & 96,2 & 9,0 \\
\hline
\end{tabular}

\section{CONCLUSÕES}

O número de grãos por espiga não se diferenciou entre as cultivares, mas o peso de mil grãos variou significativamente, com destaque para a cv. BRS Kalibre, com média de 59,3 g, contra 55,6 g e 51,8 g das cultivares BRS Brau e BRS Sampa, respectivamente.

Os níveis de produtividade de grãos obtidos foram satisfatórios, com médias de 4.870, 4.977 e $5.593 \mathrm{~kg}$ $\mathrm{ha}^{-1}$ para as cultivares BRS Sampa, BRS Brau e BRS Kalibre, respectivamente.

Embora preliminares e de um único ambiente, os resultados permitem afirmar que já existem cultivares de cevada cervejeira com boa adaptação ao ambiente avaliado, encorajando a continuidade de pesquisas de forma a contribuir para uma possível produção na região testada.

\section{AGRADECIMENTOS}

Ao Incaper, pelo apoio estrutural e logístico à Unidade de Referência em Agroecologia, local de realização do experimento; ao CNPq, pelo apoio via Bolsa de produtividade DT 2015; à FAPES pelo apoio financeiro via edital Taxa de Pesquisa 02/2015 e à Embrapa pela doação das sementes para o experimento.

\section{LITERATURA CITADA}

ALVARES, C. A.; STAPE, J. L.; SENTELHAS, P. C.; GONÇALVES, J. L. M.; SPAROVEK, G.

Köppen's climate classification map for Brazil. Meteorologische Zeitschrift, v. 22, n. 6, p. 711728, 2013.

AMABILE, R. F.; MINELLA, E.; GUERRA, A. F.; SILVA, D. B.; ALBRECHT, J. C.; ANTONIAZZI, N. BRS Deméter: nova cultivar de cevada cervejeira irrigada para o cerrado do Brasil. Pesquisa Agropecuária Brasileira, v. 43, n. 9, p. 1247-1249, 2008.

BOROWSKI, D. Z. Efeito do genótipo, ambiente e suas interações em características agronômicas e de qualidade em cevada cervejeira no sul do Brasil. Dissertação (Mestrado em Agronomia). Passo Fundo, RS: UPF, 2012. 105p.

CAIERÃO, E.; MINELLA, E.; ANTONIAZZI, N. MN 716: nova cultivar de cevada com estabilidade de produção e qualidade cervejeira. Pesquisa Agropecuária Brasileira, v. 41, n. 6, p. 1063-1065, 2006. 
COMPANHIA NACIONAL DE ABASTECIMENTO. Acompanhamento da safra brasileira de grãos Safra 2017/18 - Segundo levantamento, v. 4, n. 2, Brasília, p. 1-124, 2017.

EMBRAPA. Manual de análises químicas de solos, plantas e fertilizantes. In: DONAGEMA, G.K. et al. (Org.). $2^{\text {a }}$ ed. Revista, Rio de janeiro: Embrapa Solos, 2011.230p. (Documentos 132).

FERREIRA, C. Cultivares de cevada semeadas em espaçamentos simples e pareado combinados com doses de adubo e densidades de semeadura. Tese (Doutorado em Agronomia). Ponta Grossa, PR: UEPG, 2015. 73p.

GIARETTA, A.; SCARAVONATTI, G. M. SORDI, A.; PELLEGRINI, R. Avaliação do desempenho de cultivares de cevada em São José do Cedro/SC. In: SIEP, 2017. Anais... Joaçaba: UNOESC, 2017. (Pesquisa e Internacionalização).

\section{HAUGGAARD-NIELSEN, H.; JENSEN, E. S.}

Evaluating pea and barley cultivars for complementary in intercropping at different levels of soil N availability. Field Crop Research, v. 72, p. 185-196, 2001.

LEISTRUMAISTE, A.; PAPLAUSKIENE, V.; MASAUSKIENE, A. et al. Evaluation of spring barley varieties for breeding programmes. Latvian Journal of Agronomy, n. 11, p. 101-107, 2008.

MINELLA, E. Melhoramento da cevada. In: Melhoramento de espécies cultivadas, $2^{\mathrm{a}}$ edição. UFV, Viçosa, p. 255-299, 2009.
MINELLA, E. (Org.). Indicações técnicas para a produção de cevada cervejeira nas safras 2015 e 2016. In: $30^{\text {a }}$ Reunião Nacional de Pesquisa de Cevada, 2015. Anais... Passo Fundo: Embrapa Trigo, 2015. 106 p. (Sistemas de produção, ISSN 1806-664X, 8).

SANCHES, F. M.; CUNHA, F. F.; SANTOS, O. F. et al. Desempenho agronômico de cultivares de cevada cervejeira sob diferentes lâminas de irrigação. Semina: Ciências Agrárias, v. 36, n. 1, p. 89-102, 2015.

SIDDIQUE, K. H. M.; BELFORD, R. K.; PERRY, M. W.; TENNANT, D. Growth, development and light interception of old and modern wheat cultivars in a Mediterranean environment. Australian Journal of Agricultural Research, v. 40, p. 473-487, 1989.

SILVA, D. B.; GUERRA, A. F.; MINELLA, E.; ARIAS, G. BRS 180: cevada cervejeira para cultivo irrigado no cerrado. Pesquisa Agropecuária Brasileira, v. 35, n. 8, p. 16891694, 2000.

SOUZA, J. L.; RESENDE, P. Manual de horticultura orgânica. $3^{\text {a }}$ ed. Viçosa: Aprenda Fácil, 2014, 841p. il.

YEOMANS, J. C.; BREMNER, J. M. A rapid and precise method for routine determination of organic carbon in soil. Communications in Soil Science and Plant Analysis, v.19, p.1467-1476, 1988.

Recebido para publicação em 21/11/2018 e aprovado em 25/03/2019. 